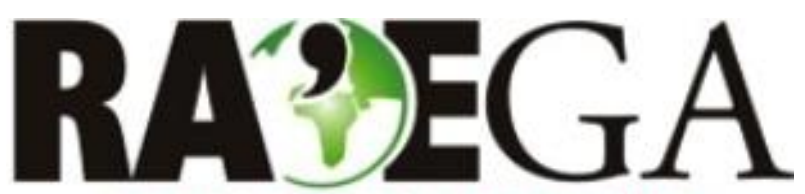

O ESPAÇO GEOGRÁFICO EM ANÁLISE

\title{
GEOTECNOLOGIAS E ANALISE ESPACIAL: PLANEJAMENTO DE MOBILIDADE COM UNIDADES BLINDADAS TIPO LAGARTA NA BACIA HIDROGRÁFICA DO LAGO DE MARACAIBO - VENEZUELA
}

\section{GEOTECHNOLOGIES AND SPATIAL ANALYSIS: MOBILITY PLANNING WITH LAGARTA - TYPE ARMORED UNITS IN THE HYDROGRAPHIC BASIN OF MARACAIBO LAKE - VENEZUELA}

\author{
Rhael David Lara Partida ${ }^{1}$, Romario Trentin ${ }^{2}$, Luís Eduardo de Souza Robaina ${ }^{3}$
}

\section{RESUMO}

O presente trabalho visa desenvolver aplicações em SIG que possibilitam subsidiar ações de estratégia militar, explorando a geração de informações sobre a bacia hidrográfica do lago de Maracaibo, valorizada como uma porção do território venezuelano caracterizada por concentrar riquezas energéticas e naturais que exigem a aplicação, de medidas de defesa militar compatíveis com as características do meio. 0 emprego das potencialidades da cartografia automatizada, onde os dados são vinculados por meio de ferramentas de geoprocessamentos, para avaliar os diferentes graus de influência dos fatores da topografia, da hidrografia, da precipitação e da vegetação com o processo de resistência ante a mobilidade militar sobre lagartas. Finalmente a partir desta compreensão, foram delimitados cinco setores classificados como ótimos, adequados, restritivos, muito restritivos e impeditivos conforme seu grau de homogeneidade em relação as potencialidades e/ou restrições. Utilizando os procedimentos e técnicas da cartografia em ambiente SIG, foi possível observar a redução de tempo de processamentos e aumento na quantidade de dados relacionados na análise geográfica militar, disponibilizando produtos para fins de planejamento estratégico.

Palavras-chave: SIG, Mobilidade Militar, Planejamento Estratégico

\section{ABSTRACT}

The present work aims to develop applications in GIS that allow to subsidize military strategy actions, exploring the generation of information about the basin of the Maracaibo lake. This area represents a portion of Venezuelan territory characterized by concentrating energetic and natural riches that require the application, measures compatible with the characteristics of the environment. The use of the potential of automated mapping with the data generating was linked through geoprocessing tools to assess the different degrees of influence of the factors such as: topography, hydrography, precipitation and vegetation with the process of resistance to military mobility on caterpillars. Finally, five sectors classified as optimal, adequate, restrictive, very restrictive and impeditive according to their degree of homogeneity in relation to potentialities and / or constraints were delimited. Using the procedures and techniques of cartography in the GIS environment, it was possible to observe the reduction of processing time and increased the amount of related data in military geographic analysis, making products available for strategic planning purposes

Key-words: GIS, Military Mobility, Strategic planning

\footnotetext{
${ }_{1}^{1}$ Fuerza Armada Nacional Boliva, Venezuela, e-mail: rhael.lara5@gmail.com

2 Universidade Federal de Santa Maria, Santa Maria/RS, e-mail: romario.trentin@gmail.com

${ }^{3}$ Universidade Federal de Santa Maria, Santa Maria/RS, e-mail: lesrobaina@yahoo.com.br
} 


\section{GEOTECNOLOGIAS E ANALISE ESPACIAL: PLANEJAMENTO DE MOBILIDADE COM UNIDADES BLINDADAS TIPO LAGARTA NA BACIA HIDROGRÁFICA DO LAGO DE MARACAIBO - VENEZUELA}

INTRODUÇÃO

$\mathrm{O}$ estudo do terreno, com fins de planejamento ao deslocamento militar, necessita de análise sistêmica utilizando uma quantidade de informações, que é facilitada mediante o emprego dos Sistemas de Informações Geográficas (SIG). Os SIG proporcionam uma grande flexibilidade e capacidade de reação frente às possíveis mudanças ocasionadas pelo aparecimento de situações inesperadas, que fazem parte da dinâmica espacial, que caracteriza os ambientes operacionais militar (HOEPERS e SANTOS, 2001; SOARES, 2006).

Atualmente um conjunto de novos métodos tem sido utilizado no intuito de contribuir com a cartografia, em uma constante tentativa na formulação de modelos para compartimentar a paisagem de forma a refletir a sua dinâmica interna e suas interações. Autores como Macmillan e Shary (2009), Vasconcelos et al. (2012), Jasiewicz e Stepinski (2013) usam ferramentas de SIG e geotecnologias para subdivisão do relevo considerando as diferenças inerentes dos atributos de terreno. Robaina et al. (2016, 2017) utilizaram variáveis geomorfométricas para compartimentar o relevo dos estados do Rio Grande do Sul e do Tocantins.

$$
\text { O trabalho de Niculiţă (2011), }
$$
apresentou uma avaliação de algoritmos computacionais e seus efeitos na identificação de elementos geomorfométrico. Já IVANOV; YERMOLAEV e SHYNBERGENOV (2016), estabeleceram uma análise correlativa entre os parâmetros geomorfométricos obtidos através da base do SRTM e do ASTER GDEM, definindo que, para uma escala generalista foram reveladas regularidades de mudanças espaciais relativas a características geomorfométricas consideradas nas duas bases cartográficas.

Diversas são as aplicações de modelagens e cruzamentos de atributos topográficos a fim de definição e análise do modelado, forma ou elementos de relevo. As aplicações geomorfométricas cada vez mais tendem a contribuir como ferramenta de análise interpretativa a fim de definir novas possibilidade de mapeamentos geomorfológicos (GALLANT; BROWN; HOFFER, 2005; DRAGUT; BLASCHKE, 2006; HANI; SATHYAMOORTHY; ASIRVADAM, 2012; GROHMANN; SAWAKUCHI, 2013)

Assim sendo, o presente trabalho procura hierarquizar e discriminar áreas, levando em conta a inter-relação das características de mobilidade da tecnologia militar blindada, propulsada sobre Lagartas e as variáveis físiconaturais da Bacia Hidrográfica do Lago de Maracaibo (Figura 1), realizado em ambientes de SIG.

A mobilidade representa o elemento da análise geográfica militar que envolve a capacidade que tem as unidades de combate, em determinado espaço geográfico, de mudar de posição; isto inclui análise de velocidades e liberdade de manobra, características físicasnaturais da área de operação e as capacidades tanto técnicas como de adestramento das unidades envolvidas (VENEZUELA, 1992). Portanto, o espaço deve ser avaliado com todas suas complexidades e especificidades que se estabelecem para facilitar, dificultar ou impedir o deslocamento de determinada força militar (RIBEIRO, 2015).

Para fins de confecção de mapas temáticos de manobra militar existem três tipos de terrenos: o impeditivo, onde são incluídas as áreas que desfavorecem ao movimento e sua utilização precisaria de forte apoio de engenharia para possibilitar uma mobilidade específica; o restritivo, para representar as áreas que limitam o movimento comprometendo sua velocidade e manobra, as quais estariam consideravelmente reduzidas se não tivessem trabalhos de apoio de engenharia militar; e o terreno adequado onde são incluídas as áreas favoráveis ao movimento de determinada tecnologia militar, com alto grau de manobra e normalmente sem requerer trabalhos de engenharia (BRASIL, 2011). 


\section{GEOTECNOLOGIAS E ANALISE ESPACIAL: PLANEJAMENTO DE MOBILIDADE COM UNIDADES BLINDADAS TIPO LAGARTA NA BACIA HIDROGRÁFICA DO LAGO DE MARACAIBO - VENEZUELA}

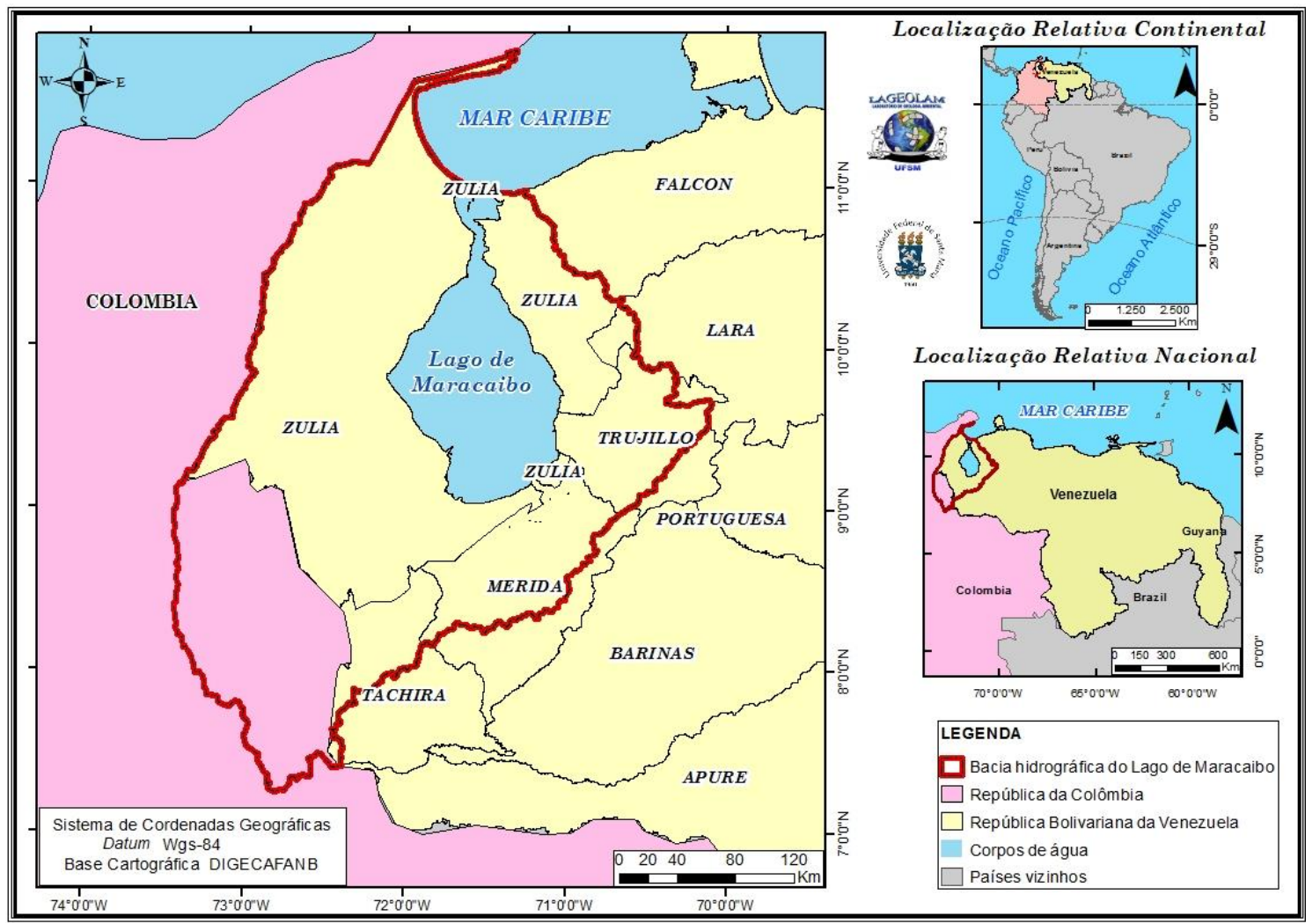

Figura 1 - Localização da bacia hidrográfica do lago de Maracaibo. Fonte: Os autores

\section{METODOLOGIA}

A base do Modelo Digital de elevação utilizada foram os dados do ASTER-GDEM que passou por correção dos erros de espaços vazios (NoData) encontrados no Modelo. O preenchimento dos espaços vazio se deu através de dados topográficos extraídos das cartas militares em escala de 1:100.000, que após processamento digital e geração do MDE foram incorporados nos vazios existentes dos dados provenientes do ASTER-GDEM. A inexistência de base topográfica contínua em escala 1:100.000 para a área de estudo, inviabilizou o uso desta para toda a área, desta forma, optou-se pelos dados do Aster-GDEM como base contínua e seus vazios preenchidos através dos dados topográficos das cartas militares.

A definição das classes hipsométricas a partir do MDT procedeu-se através da utilização da ferramenta Reclassify do $\operatorname{ArcGIS}^{\circledR}$ 10.1, para definir dois conjuntos hipsométricos ( $<0$ metros e $>0$ metros). Utilizou-se a altitude de zero metros, por existirem porções do terreno abaixo do nível do mar, com solos em situação de saturação.

Para espacializar os níveis de restrição por declividade dos blindados, tipo lagarta, foram definidas quatro classes de declividades: $<15 \%$, entre $15 \%$ e $35 \%$, entre $35 \%$ e $45 \%$ e $>45 \%$, baseado na restrição ao movimento imposto pela declividade frente a mobilidade blindada do Exército Brasileiro (BRASIL, 2011). O mapa de declividade foi elaborado a partir da utilização da ferramenta Slope e foi classificado por meio da ferramenta Reclassify.

Apesar do estudo ser de caráter regional, procurou-se estabelecer relações entre os parâmetros geomorfométricos obtidos e dados de perfil de solos na área de estudo para a espacialização. As características dos diferentes perfis de solo (NOGUERA, 2011) podem ser observadas na Figura 2. As características dos solos presentes foram relacionadas com as capacidades de resistência à pressão e os diferentes tipos de solicitações das unidades militares (Quadro 1). 


\section{GEOTECNOLOGIAS E ANALISE ESPACIAL: PLANEJAMENTO DE MOBILIDADE COM UNIDADES BLINDADAS TIPO LAGARTA NA BACIA HIDROGRÁFICA DO LAGO DE MARACAIBO - VENEZUELA}

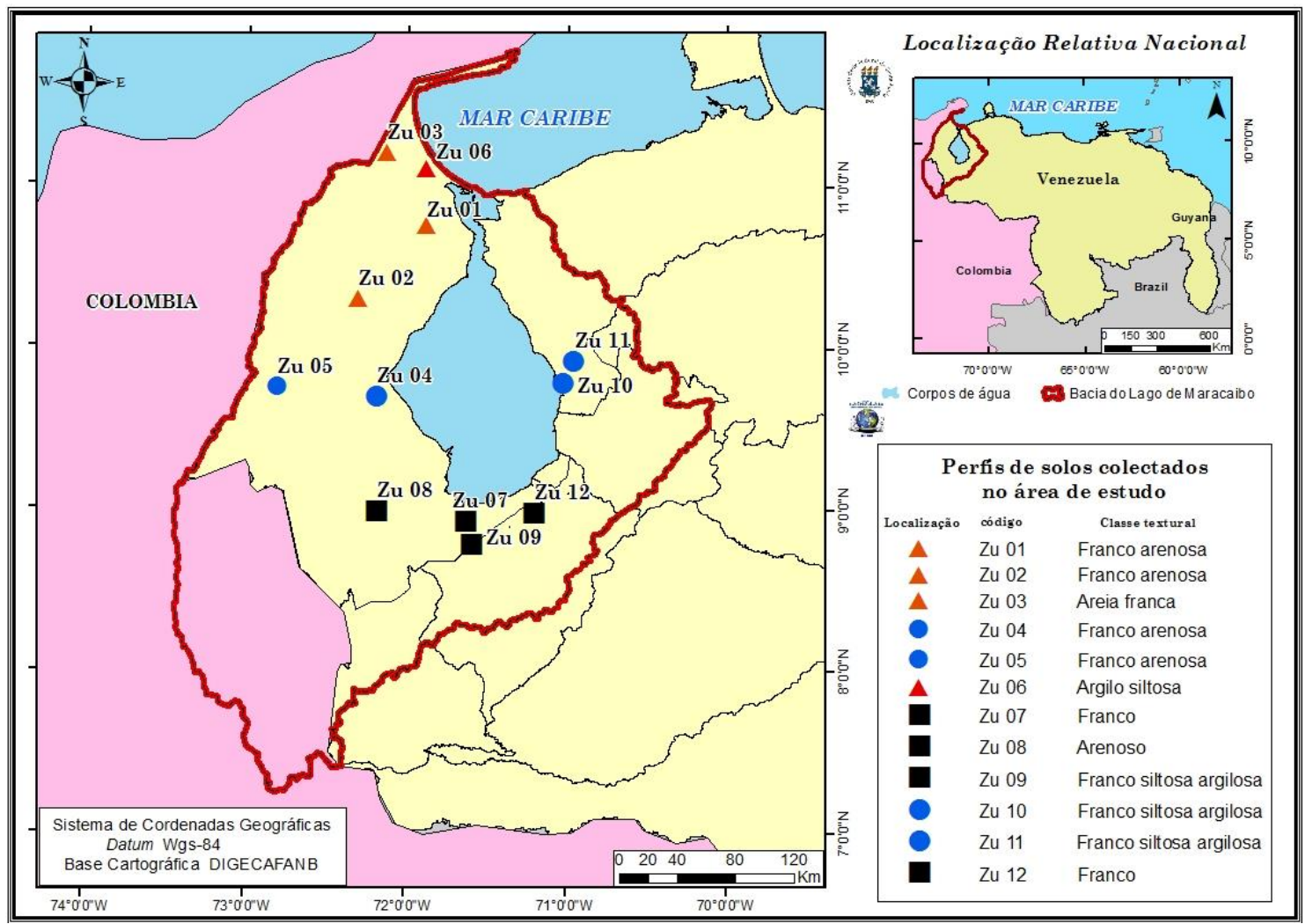

Figura 2 - Localização dos perfis de solo analisados e sua classificação textural na área de estudo. Fonte: Os autores

Quadro 1 - Classificação dos solos segundo sua resistência à pressão.

\begin{tabular}{|c|c|}
\hline CLASSIFICAÇAO & RESISTÊNCIA $\left(\mathrm{Kg} / \mathrm{cm}^{2}\right)$ \\
\hline Rochoso & 7,0 a 50,0 \\
\hline Pedregoso & 5,0 a 7,0 \\
\hline Arenoso (grosso) & 4,0 a 5,0 \\
\hline Arenoso (fino) & 3,0 a 4,0 \\
\hline Argiloso com areia & 2,0 a 3,0 \\
\hline Argiloso compacto & 1,0 a 2,0 \\
\hline Argiloso úmido & 0,75 a 1,0 \\
\hline Lamacento & 0,5 a 0,75 \\
\hline Pantanoso & $<0,5$ \\
\hline
\end{tabular}

Fonte: Brasil (2011).

As unidades geomorfométricas foram identificadas através do cruzamento dos atributos topográficos (altimetria, declividade, perfil de curvatura e plano de curvatura) gerados por meio do SIG e hierarquizados através de uma árvore de decisão, apresentado no fluxograma da Figura 3. 


\section{GEOTECNOLOGIAS E ANALISE ESPACIAL: PLANEJAMENTO DE MOBILIDADE COM UNIDADES BLINDADAS TIPO LAGARTA NA BACIA HIDROGRÁFICA DO LAGO DE MARACAIBO - VENEZUELA}

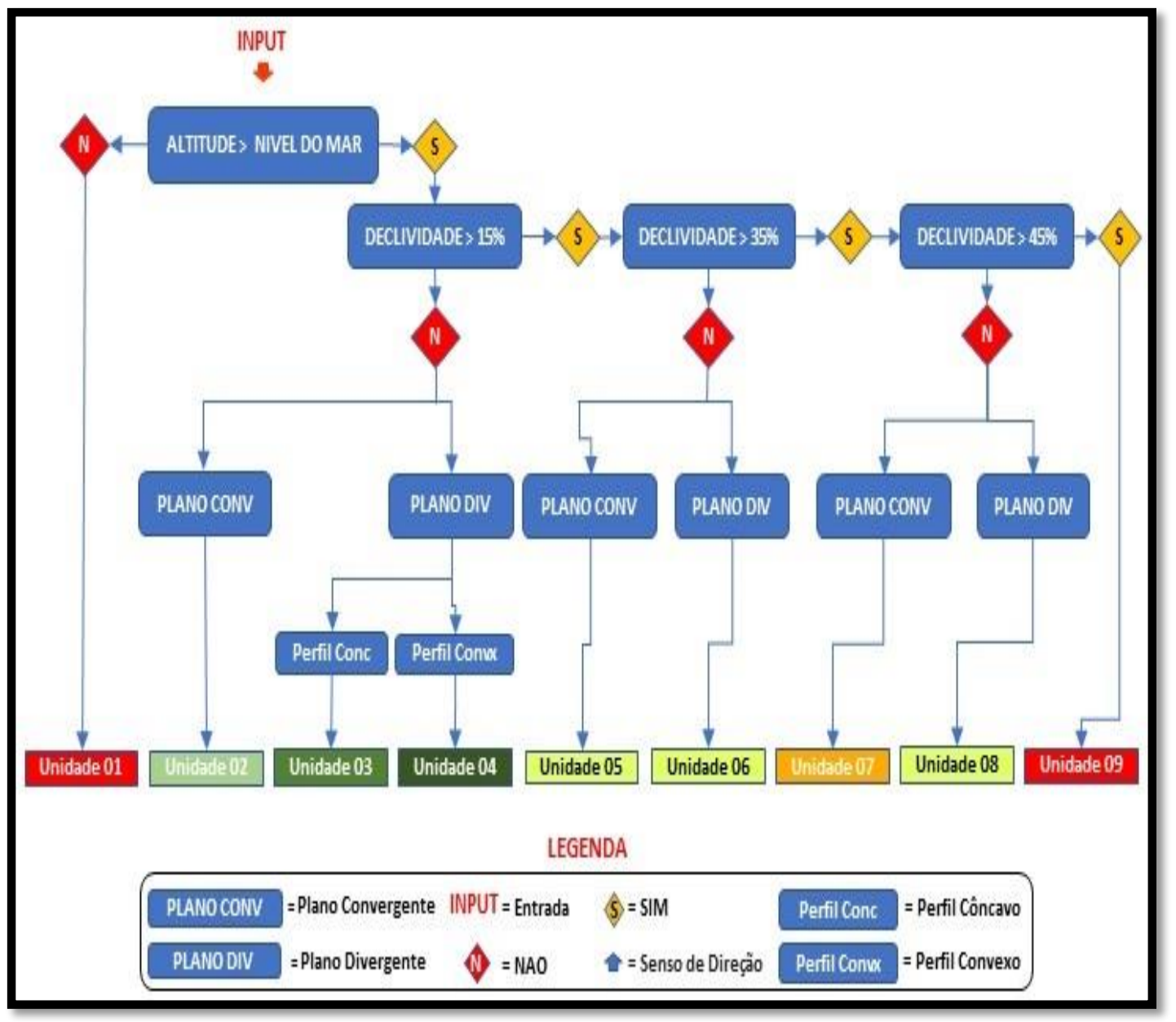

Figura 3 - Fluxograma apresentando a árvore de decisão utilizada para a definição das unidades geomorfométricas. Fonte: Os autores

A modelagem digital do relevo é uma das técnicas quantitativas melhor desenvolvidas para predizer atributos e classes de solos (McKENZIE et al., 2000). Uma vez caracterizada, cada unidade geomorfométrica foi relacionada com os ambientes formadores de solos, relacionadas com ambientes formadores de solos, procedendo a sua hierarquização em cinco classes: rocha exposta, solos rasos, solos bem desenvolvidos, solos bem desenvolvidos com fluxo linear concentrado, solos saturados. Mediante o uso da ferramenta Reclassify, para atribuir valores em relação a seus graus de influência, onde o valor zero (00) foi outorgado às unidades com impedimento e o valor quatro (04) às unidades com o menor grau de resistência.

A análise hidrografia passou inicialmente por um processo de correção dos dados, através da sobreposição da base vetorial extraída das cartas militares sobre as imagens do satélite LANDSAT 8, tendo sua complementação espacial realizada através da extração automatizada dos cursos de água pelas ferramentas SIG utilizando-se limiares de acumulação de fluxo compatíveis com a escala de análise. Os vetores resultantes deste processo de edição e ajuste foram hierarquizados com o propósito de viabilizar a sua vinculação com os níveis de restrição ao movimento blindado sugeridos por Brasil (2011) e conforme representa o Quadro 2. 


\section{GEOTECNOLOGIAS E ANALISE ESPACIAL: PLANEJAMENTO DE MOBILIDADE COM UNIDADES BLINDADAS TIPO LAGARTA NA BACIA HIDROGRÁFICA DO LAGO DE MARACAIBO - VENEZUELA}

Quadro 2 - Restrições ao movimento impostas pela Hidrografia.

\begin{tabular}{|c|c|c|}
\hline $\begin{array}{l}\text { CLASSIFICAÇÃO } \\
\text { DO TERRENO }\end{array}$ & HIERARQUIA & HIDROGRAFIA \\
\hline Impeditivo & 6a Ordem & $\begin{array}{l}\text { Cursos d'água, lagos, pântanos, zonas alagadiças, que não possam ser cruzados } \\
\text { ou atravessados. Margens verticais de superfície firme, que possam deter os } \\
\text { carros-de-combate, assim como a correnteza com velocidade elevada e } \\
\text { profundidade que apresente desvantagens para viaturas blindadas (Lagartas). }\end{array}$ \\
\hline Muito restritivo & 5a Ordem & \multirow{2}{*}{$\begin{array}{l}\text { Cursos d'água, lagos, áreas alagadiças, que possam ser cruzados ou atravessados } \\
\text { com lagartas em vários locais. A velocidade da correnteza deve ser pequena }(<1,5 \\
\mathrm{m} / \mathrm{s}) \text { e a profundidade deve ser inferior a } 1,20 \mathrm{~m} \text {. }\end{array}$} \\
\hline Restritivo & 4a Ordem & \\
\hline Adequado & 3aㅡ Ordem & \multirow{2}{*}{$\begin{array}{l}\text { Cursos d'água, lagos, que possam ser cruzados em qualquer lugar ou que tenham } \\
\text { largura }<1,5 \mathrm{~m} \text {. A profundidade de }<0,6 \mathrm{~m} \text { e a velocidade da correnteza não deve } \\
\text { impedir a travessia do tipo lagarta. }\end{array}$} \\
\hline Ótimo & 1a e 2a Ordem & \\
\hline
\end{tabular}

Fonte: Adaptado de Brasil (2011).

A variável de precipitação levou em consideração os setores que, dentro do microclima da bacia, apresentam menos exposição à presença de chuvas (valores de pluviosidade acumulada menores que $1.032 \mathrm{~mm}$ ) que são classificados como mais adequados à mobilidade de blindados tipo lagarta, enquanto os setores que estão submetidos aos valores de pluviosidade acumulada maiores que $2.255 \mathrm{~mm}$ ) são classificados como impeditivos.

Foram utilizados os dados pluviométricos em formato raster com 1 (um) km de resolução espacial fornecidos com um $1 \mathrm{~km}$ de resolução espacial fornecidos de forma gratuita pela University of Califórnia "The WorldClim interpolated global terrestrial climate surfaces. Version 2.0."

Por meio do emprego da ferramenta Raster Calculator do módulo Spatial Analyst Tool foram somados os valores da série histórica (1970-2000), procedimento mediante o qual obteve-se os dados de precipitação total acumulada para a área de estudo, que foram reclassificados por meio da ferramenta Reclassify selecionando o método de rupturas natural (Jenks) com o objetivo de dividir os valores de pluviosidade acumulada da área de estudo em classes.

A camada de restrição ao movimento devido à vegetação, foi realizada a partir do NDVI de imagens MODIS captadas na área de estudo pela National Aeronautics and Space Administration (NASA) durante o ano de 2017. Posteriormente as 24 imagens correspondentes a série do ano 2017, foram sobrepostas para gerar um novo raster que selecionou o maior valor de píxel (NDVI) disponível em cada setor da bacia. A partir desta informação em formato raster, foi realizada tanto a classificação como a hierarquização dos dados de vegetação disponíveis da área de estudo (Quadro 3), ante a mobilidade blindada sobre lagartas empregando os critérios de restrição por vegetação sugeridos pelo Exército Brasileiro (BRASIL 2011).

Quadro 3 - Restrições Impostas pela Vegetação.

\begin{tabular}{|c|c|c|}
\hline $\begin{array}{l}\text { CLASSIFICAÇÃO DO } \\
\text { TERRENO }\end{array}$ & NDVI & VEGETAÇÃO \\
\hline Impeditivo & $\begin{array}{c}>0,85 \\
\text { (Bosque denso) }\end{array}$ & $\begin{array}{l}\text { Grupo de árvores que impedem o emprego de forças blindadas ou } \\
\text { dificultem o movimento de tropas a pé. }\end{array}$ \\
\hline Muito restritivo & $\begin{array}{c}0,75 \text { a } 0,85 \\
\text { (Bosques com alta } \\
\text { intervenção) }\end{array}$ & \multirow{2}{*}{$\begin{array}{l}\text { Árvores espaçadas com diâmetros reduzidos que restrinjam o } \\
\text { movimento de forças blindadas. }\end{array}$} \\
\hline Restritivo & $\begin{array}{c}\text { 0,61 a 0,75 } \\
\text { (Espinales densos } \\
\text { e Bosques com alta } \\
\text { intervenção) }\end{array}$ & \\
\hline Adequado & $\begin{array}{c}0,38 \text { a } 0,61 \\
\text { (Espinales ralos) }\end{array}$ & \multirow[t]{2}{*}{$\begin{array}{l}\text { Árvores espaçadas com diâmetros reduzidos, não interferindo no } \\
\text { emprego de viaturas ou tropas a pé. }\end{array}$} \\
\hline Ótimo & $\begin{array}{c}<0,38 \\
\text { (Solos expostos) }\end{array}$ & \\
\hline
\end{tabular}

Fonte: Brasil (2011). 


\section{GEOTECNOLOGIAS E ANALISE ESPACIAL: PLANEJAMENTO DE MOBILIDADE COM UNIDADES BLINDADAS TIPO LAGARTA NA BACIA HIDROGRÁFICA DO LAGO DE MARACAIBO - VENEZUELA}

Para a geração da análise final de hierarquização e discriminação foi utilizada a ferramenta Raster Calculator disponível na seção Map Algebra do Spatial Analyst Tools no software $\operatorname{ArcGIS}^{\circledR} 10$, onde por meio da operação multiplicação de camadas raster se consegue integrar os diferentes raster de restrição ao movimento blindado, conforme representa a Figura 04 e Quadro 4.
A classificação dos valores compreendidos entre 0 e 256, resultantes da multiplicação dos quatro (04) níveis de restrição analisados, foi obtida empregando-se o método ruptura natural (Jenks) da ferramenta Reclassify do módulo Spatial Analyst Tool disponível no software $\operatorname{ArcGIS}^{\circledR}$ 10.1, para discriminar cinco (05) classes de restrições ao movimento blindado.

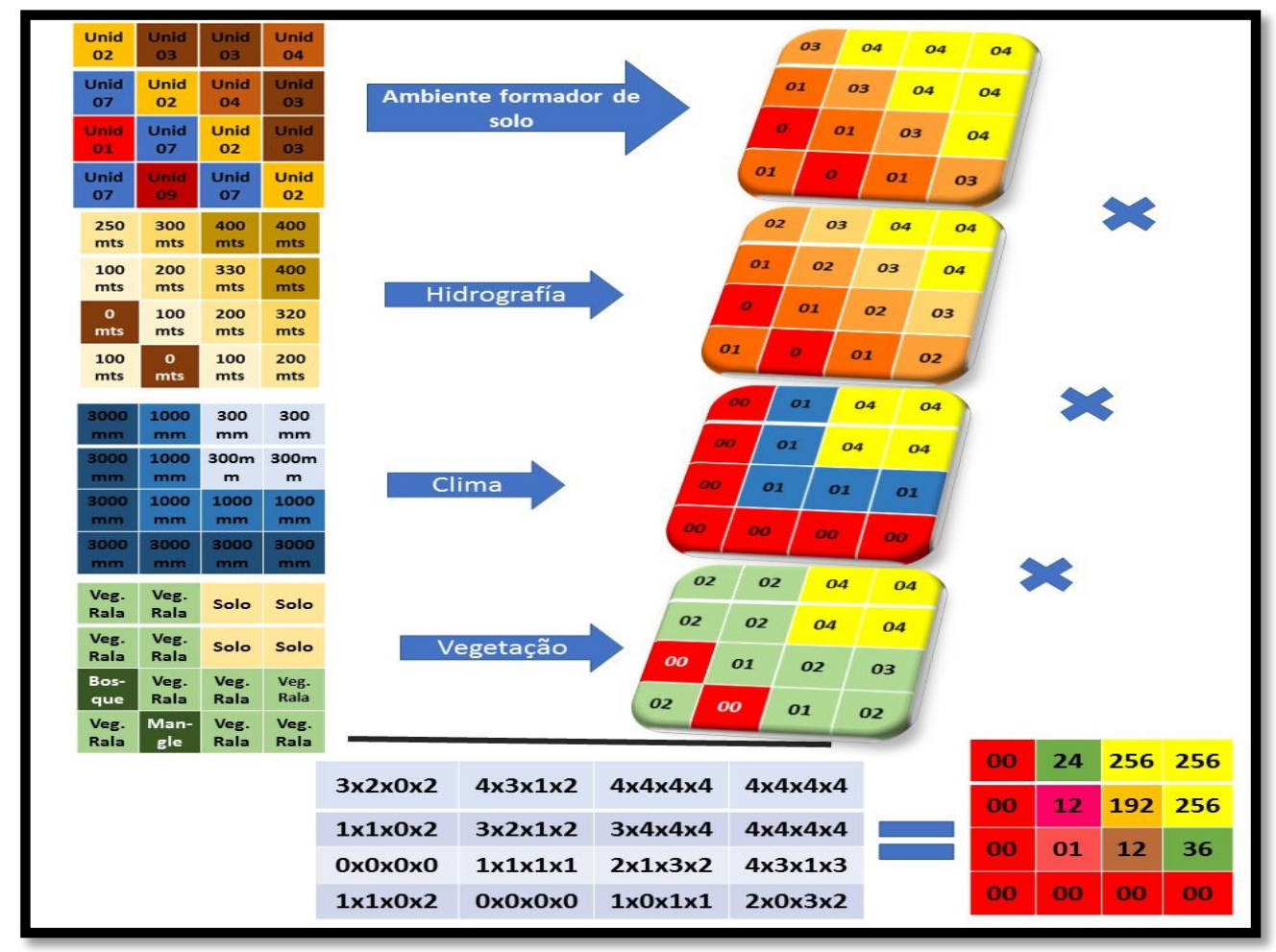

Figura 4 - Representação do processo de multiplicação de capas raster. Fonte: Os autores

Quadro 4 - Síntese dos parâmetros de classificação da área de estudo.

\begin{tabular}{|c|c|c|c|c|}
\hline Áreas & $\begin{array}{l}\text { DeclividadeAmbientes formadores } \\
\text { de solos }\end{array}$ & Hidrografia & $\begin{array}{l}\text { Precipitação } \\
\text { acumulada }\end{array}$ & $\begin{array}{l}\text { Vegetação } \\
\text { NDVI }\end{array}$ \\
\hline Ótimas & $\begin{array}{c}\text { Declividades }<15 \% \text { com planos } \\
\text { divergentes }\end{array}$ & $\begin{array}{c}\text { Primeira } 1 \mathrm{e} \\
\text { segunda } 2 \text { Ordem }\end{array}$ & $<1.032 \mathrm{~mm}$ & $\begin{array}{c}\text { Solos expostos } \\
(<0,38)\end{array}$ \\
\hline Restritivas & Declividades entre (35\% - 45\%) & Quarta (4) Ordem & $(1.371-1.768) \mathrm{mm}$ & $\begin{array}{c}\text { Espinales densos e } \\
\text { Bosques com alta } \\
\text { intervenção }(0,61 \text { - } \\
0,75)\end{array}$ \\
\hline Muito restritiva & Declividades > 45\% & Quinta (5) Ordem & $(1.768-2.255) \mathrm{mm}$ & $\begin{array}{c}\text { Bosques com alta } \\
\text { intervenção }(0,75 \text { - } \\
0,85)\end{array}$ \\
\hline Impeditivas & $\begin{array}{c}\text { Alturas } \leq 0 \text { metros } \\
\text { Declividades }>45 \%\end{array}$ & Sexta (6) Ordem & $>2.255 \mathrm{~mm}$ & $\begin{array}{c}\text { Bosque denso } \\
(>0,85)\end{array}$ \\
\hline
\end{tabular}




\section{GEOTECNOLOGIAS E ANALISE ESPACIAL: PLANEJAMENTO DE MOBILIDADE COM UNIDADES BLINDADAS TIPO LAGARTA NA BACIA HIDROGRÁFICA DO LAGO DE MARACAIBO - VENEZUELA}

\section{RESULTADOS E DISCUSSÕES}

A bacia hidrográfica do Lago de Maracaibo ocupa uma área de 79.844,92 km², localizados na parte noroeste da República Bolivariana da Venezuela. As maiores altitudes localizam-se nas cristas dos conjuntos montanhosos que a circundam como na Serra de Perijá (parte ocidental) onde atinge cotas de 3.200 metros, no Paramo de Tamá (parte sul) de 3.320 metros e no pico Bolívar na Cordilheira de Mérida registra-se as maiores altitudes do sistema com cotas que atingem os 4.912 metros. Nas planícies rebaixadas, resultantes dos processos morfotectônicos que deram origem a bacia, as cotas atingem os -47 metros, resultando em uma amplitude altimétrica de 4.865 metros.

\section{ANÁLISE DO GRAU DE RESTRIÇÃO AO MOVIMENTO DOS BLINDADOS}

A análise do fator solo foi sustentada pela compartimentação geomorfométrica da área de estudo (Figura 05) e empregada como marco cartográfico que permitiu discriminar os diferentes ambientes formadores de solo presentes na bacia.

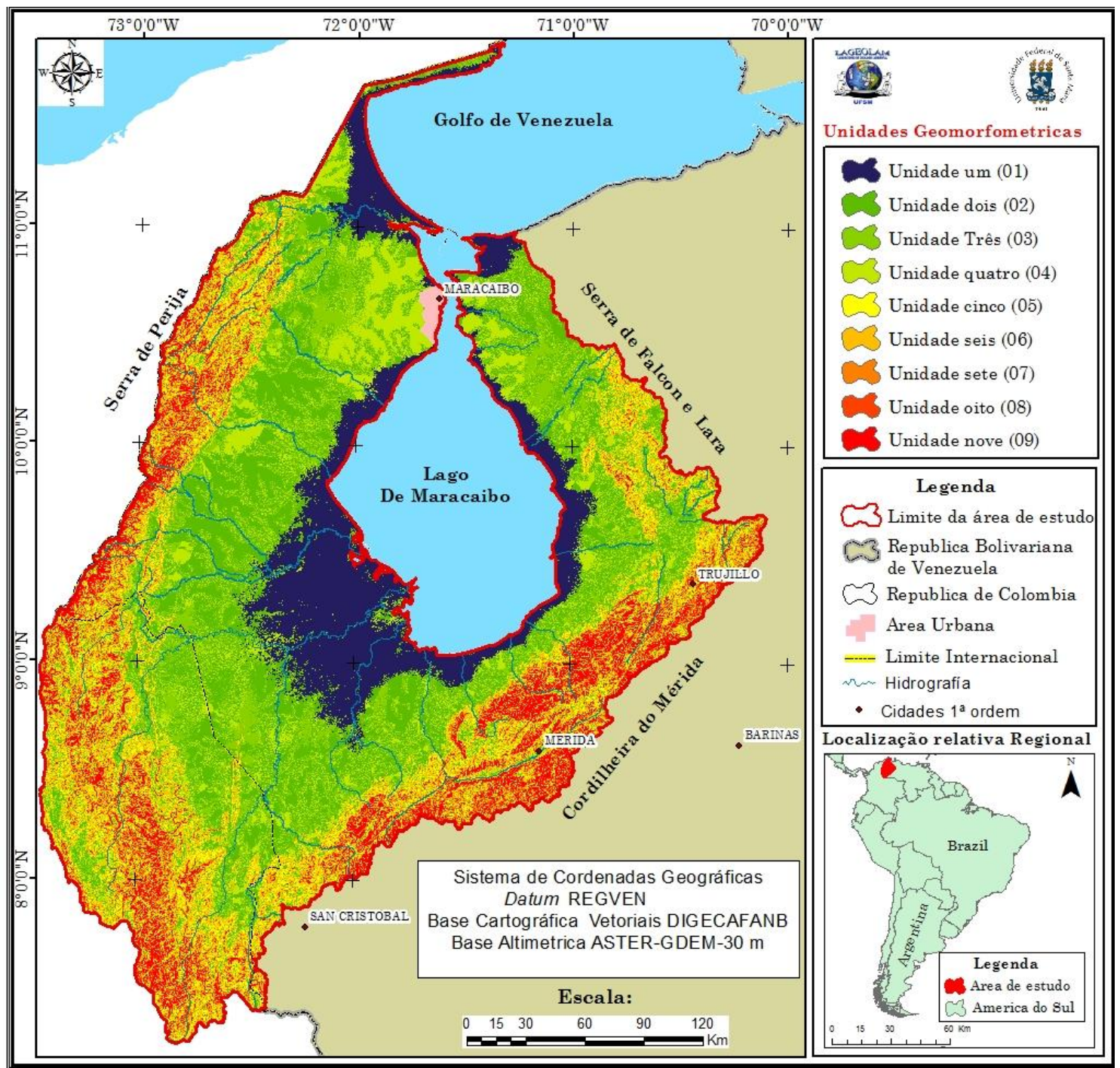

Figura 5 - Compartimentação geomorfométrica da área de estudo. Fonte: Os autores

Os solos classificados como impeditivos estão representados em setores cartograficamente delimitados pelas unidades geomorfométricas 01 e 09, que compreendem 


\section{GEOTECNOLOGIAS E ANALISE ESPACIAL: PLANEJAMENTO DE MOBILIDADE COM UNIDADES BLINDADAS TIPO LAGARTA NA BACIA HIDROGRÁFICA DO LAGO DE MARACAIBO - VENEZUELA}

uma área total $16.303,88 \mathrm{~km}^{2}$, correspondendo a $20,42 \%$ do total. A unidade 01 demarca setores com altitudes menores ou muito próximos à cota de 0 (zero) metros, localizados nas margens pantanosas das águas do lago, onde os solos são saturados. Por sua vez, a unidade 09 demarca setores localizados nas cristas das montanhas que bordejam a área de estudo, onde as declividades superiores a $45 \%$ impedem tecnicamente o movimento desta tecnologia militar.

Os solos onde o movimento blindado do tipo lagarta é muito comprometido, se encontram demarcados cartograficamente pela unidade geomorfométrica 07 . Essa unidade ocupa uma superfície de 2.556,85 $\mathrm{km}^{2}$ que representa $3,20 \%$ do total da área de estudo. Está localizado, predominantemente, nos setores montanhosos, onde as altas declividades compreendidas entre $35 \%$ e $45 \%$, e planos convergentes intensificam as atividades erosivas.

Os ambientes com solos restritos são pertencentes às unidades geomorfométricas 05, 06 e 08, que ocupam 19.499,18 km², representam $24,42 \%$ da área de estudo. A unidade 05 e 06 demarcam os ambientes localizados em áreas de piedemonte, com variações de processos de deposição e erosão. A unidade 08 cobre setores de alta montanha, com declividades entre $35 \%$ e $45 \%$, com planos divergentes.
Ambientes com solos adequados estão representados pela unidade geomorfométrica 02 , que cobre 20.708,02 $\mathrm{km}^{2}$, correspondendo a $25,94 \%$ da área total da bacia. Ocorrem de forma expressiva nas zonas de planície aluvial da bacia hidrográfica, com declividades inferiores a 15\%.

Os solos com maiores aptidões para o movimento blindado do tipo lagarta, são os delimitados cartograficamente pelas unidades geomorfométricas 03 e 04 . A unidade 03 demarca setores da planície aluvial com declividades inferiores a 15\%, com dispersão dos fluxos de água favorecem a presença de solos secos e compostos de granulometria mais grossa. Os ambientes geomorfométricos formadores de solos ótimos ocupam 20.777,05 $\mathrm{km}^{2}$, que representa $26,02 \%$ da área de estudo, são mais expressivas e consistentes na porção norte da bacia hidrográfica, onde se localizam os solos mais antigos do sistema desenvolvidos, com presença de solos secos conformados em sua capa superficial por areias e, nesse sentido, os veículos blindados do tipo lagarta utilizados neste setor atingem seus máximos níveis de eficiência operativa, razão pela qual foram considerados com o máximo valor (04) para sua integração na análise final.

A Figura 06 mostra o mapa de distribuição dos ambientes geomorfométricos formadores de solos classificados por níveis de resistências homogêneas ante o movimento de unidades blindadas tipo lagartas. 


\section{GEOTECNOLOGIAS E ANALISE ESPACIAL: PLANEJAMENTO DE MOBILIDADE COM UNIDADES BLINDADAS TIPO LAGARTA NA BACIA HIDROGRÁFICA DO LAGO DE MARACAIBO - VENEZUELA}

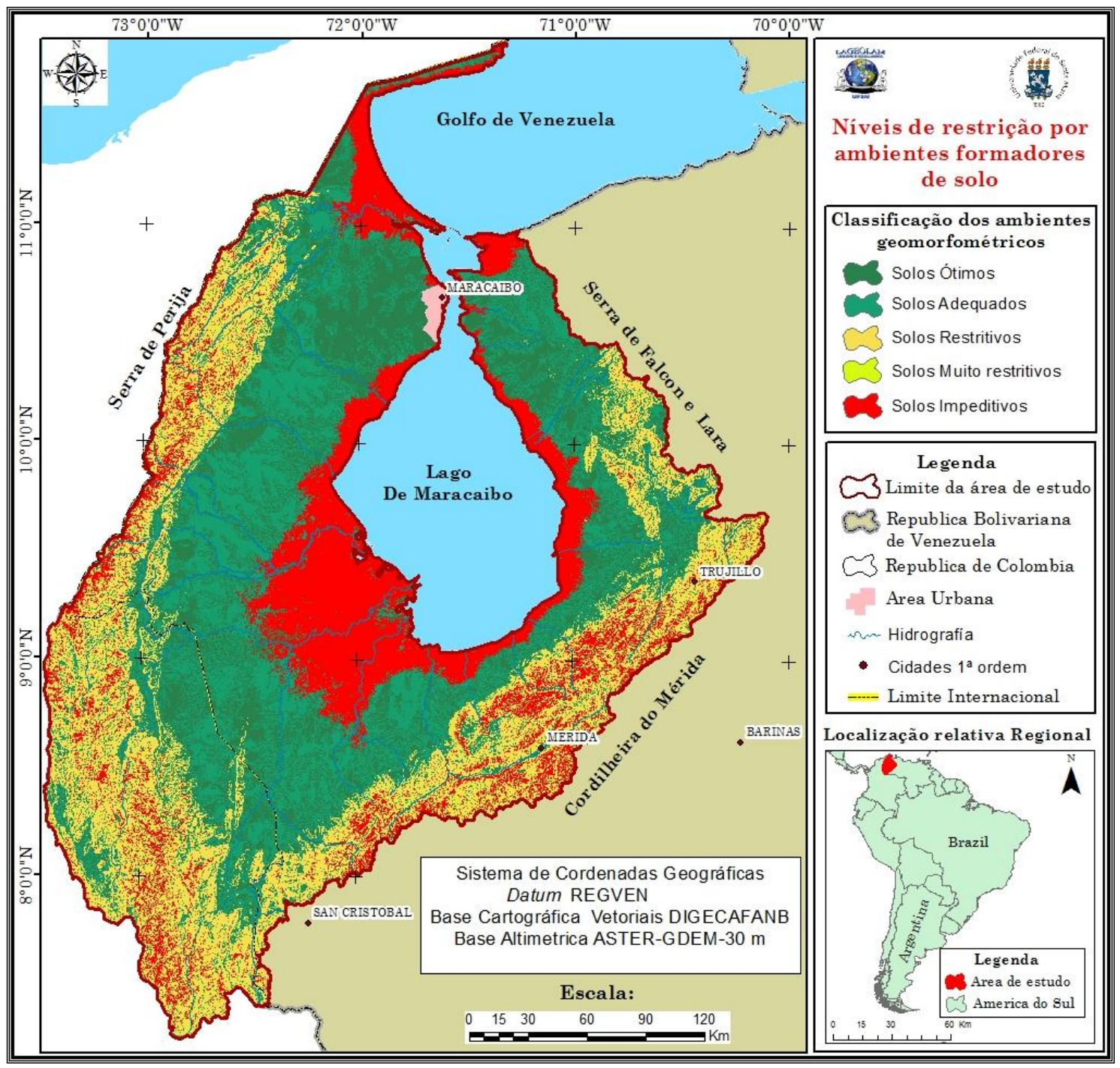

Figura 6 - Níveis de restrição ao movimento blindado por ambientes geomorfométricos formadores de solos. Fonte: Os autores

O segundo fator analisado foi a hidrografia, que é fortemente influenciada pela tectônica e a distribuição espacial que adquirem as chuvas dentro do sistema natural da bacia hidrográfica do Lago de Maracaibo, repercutindo na formação de um regime hídrico integrado por 7.736 cursos de água que somam 17.793,16 km de extensão com deslocamento centrípeto para a parte mais baixa da depressão. (Figura 07). 


\section{GEOTECNOLOGIAS E ANALISE ESPACIAL: PLANEJAMENTO DE MOBILIDADE COM UNIDADES BLINDADAS TIPO LAGARTA NA BACIA HIDROGRÁFICA DO LAGO DE MARACAIBO - VENEZUELA}

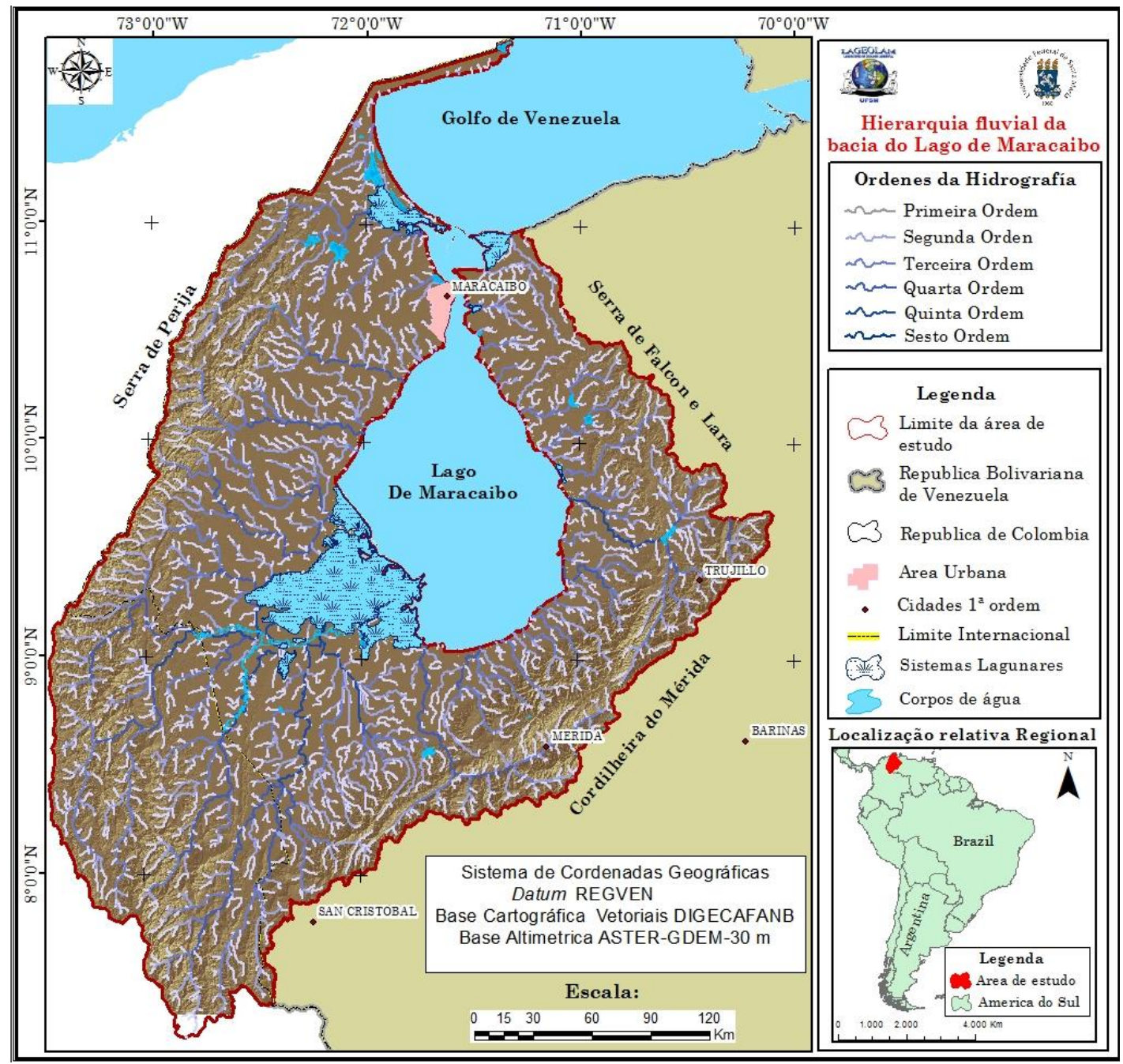

Figura 7 - Hierarquia fluvial da bacia hidrográfica do Lago de Maracaibo. Fonte: Os autores.

A hidrografia tem caráter impeditivo em 15 rios de sexta ordem, que somam dentro da área de estudo $62,63 \mathrm{~km}$ de extensão que representam $0,35 \%$ do total da rede hidrográfica da bacia.

As condições de muita restrição estão representadas por 228 segmentos de rios de quinta ordem, que somam dentro da área de estudo $561,59 \mathrm{~km}$ de extensão que representam $3,16 \%$ do total da rede hidrográfica da bacia.

Condições de restrição são observadas em 481 canais de rios de quarta ordem, que somam dentro da área de estudo $1.262,59 \mathrm{~km}$ de extensão representando $7,10 \%$ do total da rede hidrográfica da bacia.
A hidrografia se apresenta adequada em 974 segmentos de rios de terceira ordem, que somam dentro da área de estudo $2.548,62 \mathrm{~km}$ de extensão que representam $14,32 \%$ do total da rede hidrográfica da bacia.

As condições ótimas são formadas por 6.038 correntes de rios de primeira e segunda ordem, que somam dentro da área de estudo $13.357,74 \mathrm{~km}$ de extensão que representam $75,07 \%$ do total da rede hidrográfica da bacia, sobre as quais os blindados do tipo lagarta podem transitar sem nenhum tipo de dificuldade que repercuta em sua efetividade operacional.

A Figura 08 mostra o mapa de distribuição dos diferentes tipos de resistências hídricas agrupadas por parâmetros de homogeneidade ante o movimento blindado sobre lagarta. 


\section{GEOTECNOLOGIAS E ANALISE ESPACIAL: PLANEJAMENTO DE MOBILIDADE COM UNIDADES BLINDADAS TIPO LAGARTA NA BACIA HIDROGRÁFICA DO LAGO DE MARACAIBO - VENEZUELA}

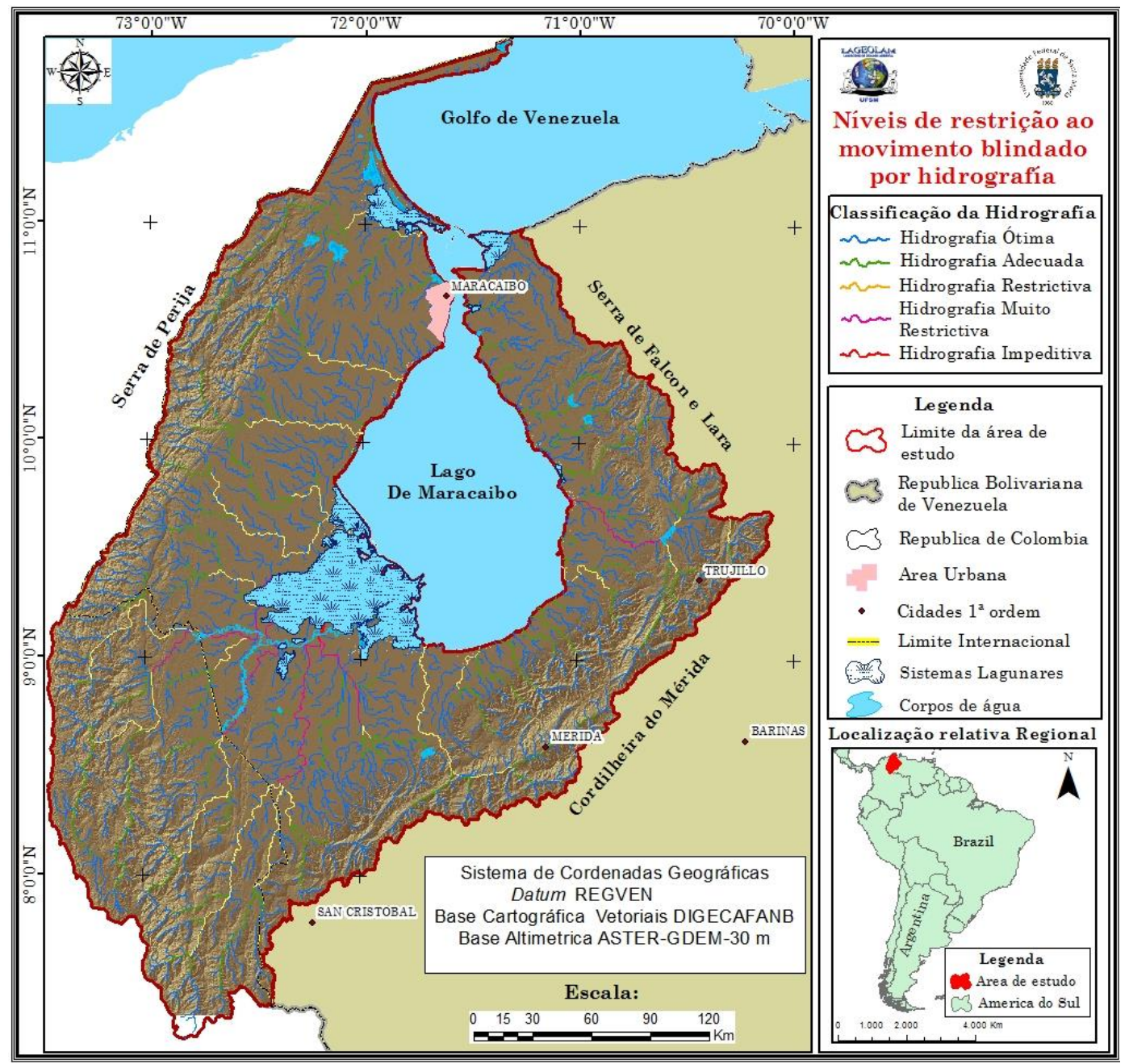

Figura 8 - Níveis de restrição ao movimento blindado pela hidrografia. Fonte: Os autores

O fator representado pelas precipitações é um dos que modifica drasticamente a transição blindada sobre lagartas. A distribuição espacial das chuvas dentro da área de estudo está apresentada na Figura 09. 


\section{GEOTECNOLOGIAS E ANALISE ESPACIAL: PLANEJAMENTO DE MOBILIDADE COM UNIDADES BLINDADAS TIPO LAGARTA NA BACIA HIDROGRÁFICA DO LAGO DE MARACAIBO - VENEZUELA}

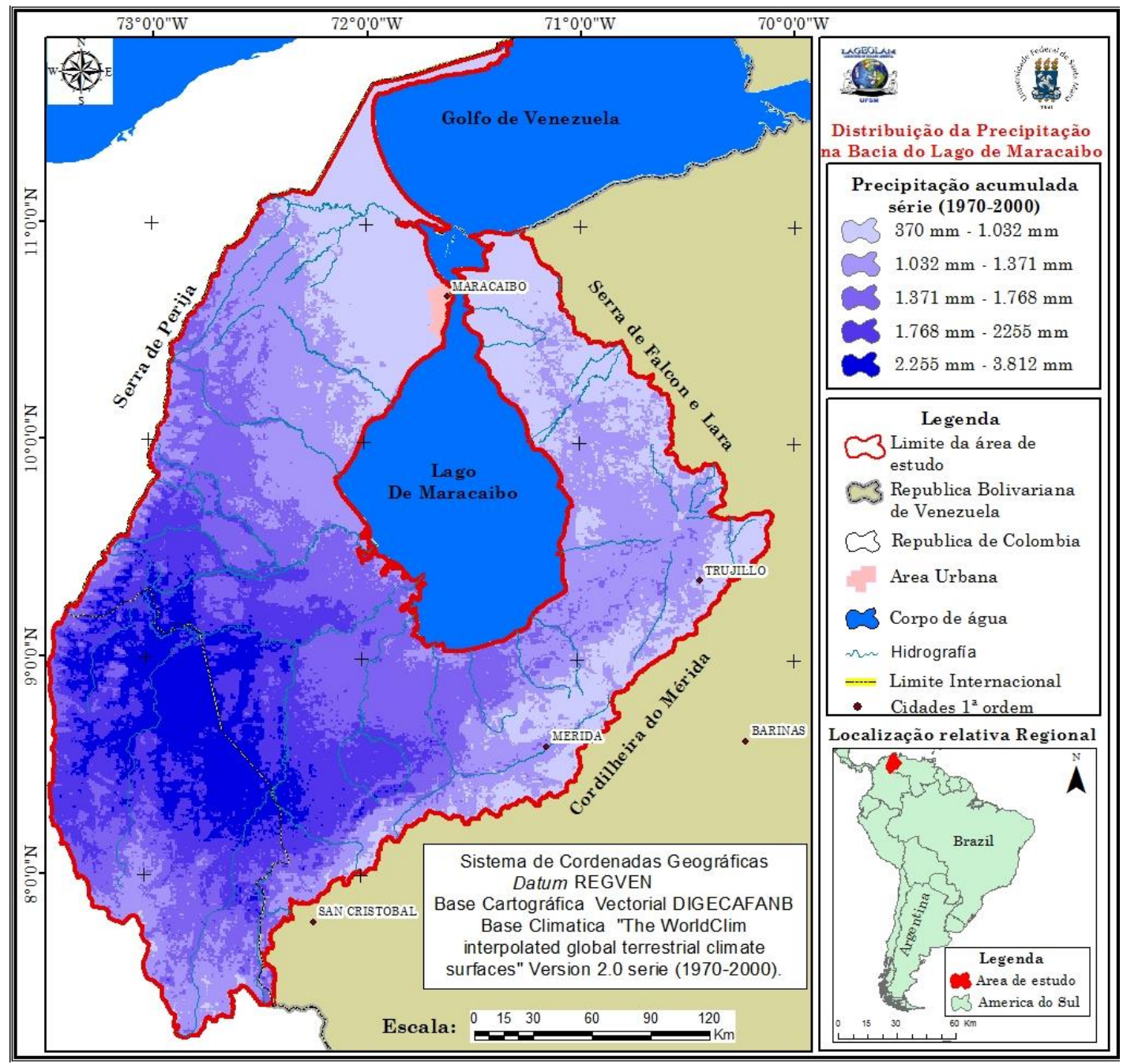

Figura 9 - Precipitação acumulada da Bacia Hidrográfica do Lago de Maracaibo série (1970-2000). Fonte: Os autores

A área com precipitação impeditiva corresponde a 7.946,96 $\mathrm{km}^{2}$ que representam $9,95 \%$ do total da área de estudo. Nestes setores estão predominantemente localizados na alta montanha do sul e oeste da bacia.

Setores com precipitação muito restritiva são localizados na parte sul ocidental da bacia hidrográfica os efeitos das chuvas constantes ocasionam frequentes inundações. Correspondem a $13.181,54 \mathrm{~km}^{2}$, representando $16,51 \%$ do total da área de estudo.

Áreas com precipitação restrita ocorrem em $17.996,86 \mathrm{~km}^{2}$ que representam $22,54 \%$ do total da área de estudo, predominantemente localizados na planície aluvial da parte sul da bacia hidrográfica.
Nível adequado está formado por áreas que apresentam uma faixa de precipitação acumulada compreendida entre os $1.032 \mathrm{~mm}$ até os $1.371 \mathrm{~mm}$, que correspondem a $22.943,33 \mathrm{~km}^{2}$ que constituem $28,73 \%$ do total da área de estudo, predominantemente localizados na planície aluvial da parte média da bacia e em menor proporção no piedemonte da Serra de Perijá ao noroeste da área de estudo.

As condições ótimas ocorrem em $17.776,24 \mathrm{~km}^{2}$ que representam $22,26 \%$ do total da área de estudo e se encontram, predominantemente, localizados na parte norte da bacia hidrográfica, com ênfase em sua porção ocidental.

A Figura 10 mostra o mapa de distribuição dos diferentes tipos de resistências 


\section{GEOTECNOLOGIAS E ANALISE ESPACIAL: PLANEJAMENTO DE MOBILIDADE COM UNIDADES BLINDADAS TIPO LAGARTA NA BACIA HIDROGRÁFICA DO LAGO DE MARACAIBO - VENEZUELA}

ante o movimento blindado sobre lagarta imposto pela precipitação da área de estudo.

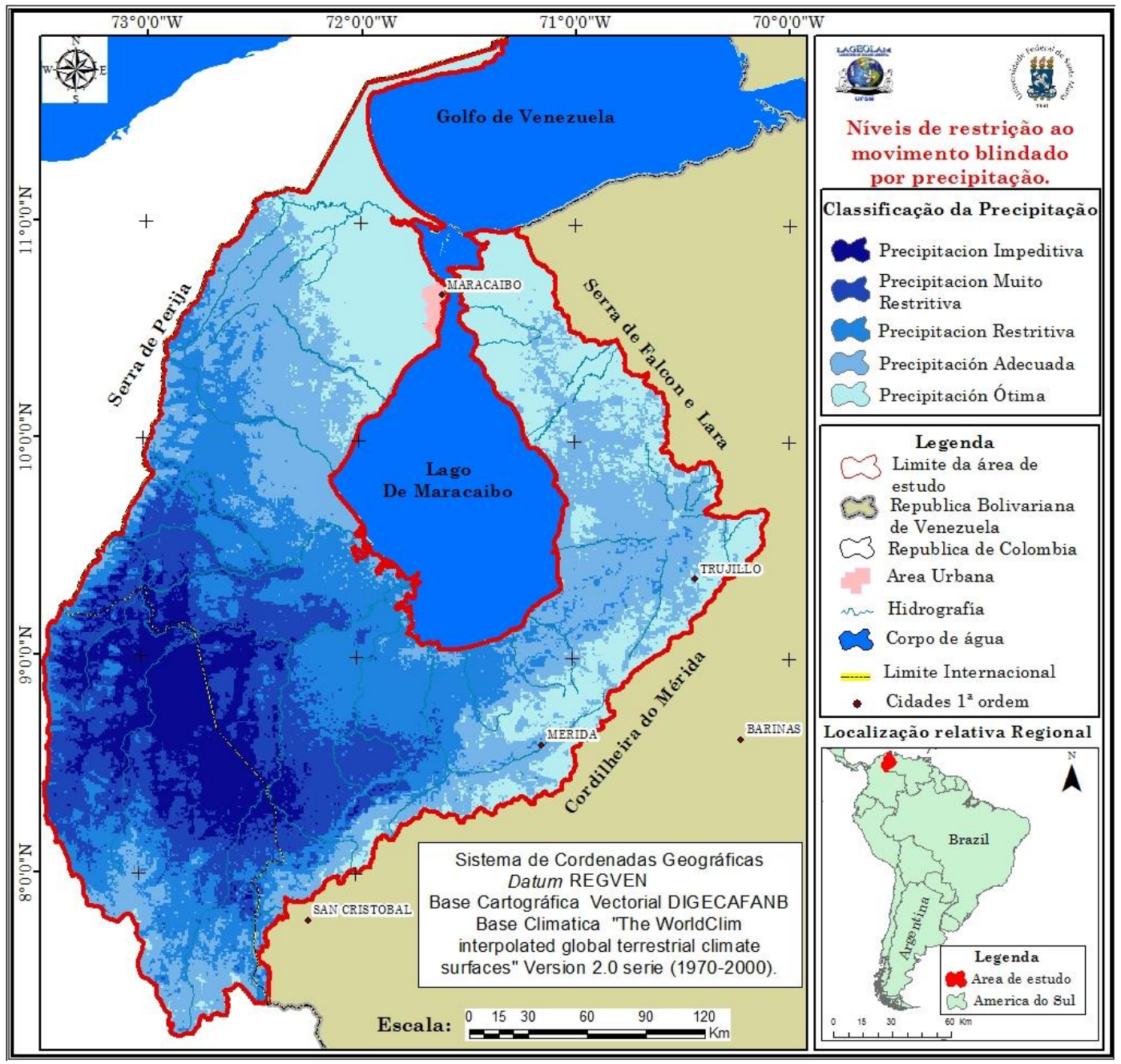

Figura 10 - Níveis de restrição ao movimento blindado por precipitação. Fonte: Os autores

O quarto fator considerado foi a cobertura vegetal, que é classificada em função da distribuição dos diferentes tipos de níveis de resistências ante o movimento blindado sobre lagarta (Figura 11).

As características da vegetação tornam a área impeditiva em 33.016,23 $\mathrm{km}^{2}$ que representa $41,35 \%$ do total da área de estudo. Estes setores estão localizados no bosque de alta montanha que circunda a área de estudo, nos bosques de galeria da parte central e na área alagada do sul da bacia hidrográfica. 


\section{GEOTECNOLOGIAS E ANALISE ESPACIAL: PLANEJAMENTO DE MOBILIDADE COM UNIDADES BLINDADAS TIPO LAGARTA NA BACIA HIDROGRÁFICA DO LAGO DE MARACAIBO - VENEZUELA}

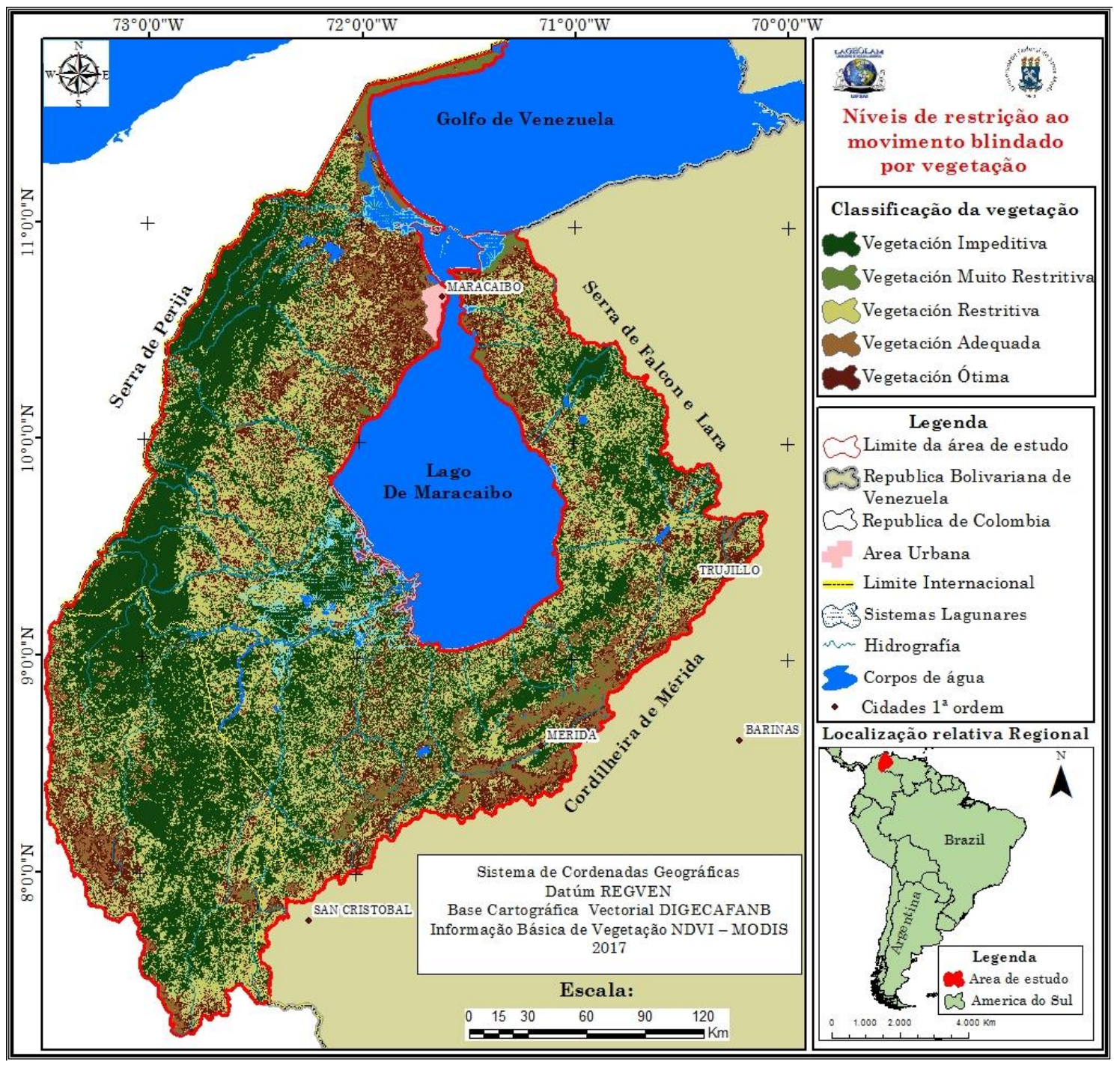

Figura 11 - Níveis de restrição ao movimento blindado por vegetação. Fonte: Os autores

As condições de muita restrição correspondem a 2.031,64 $\mathrm{km}^{2}$ e representam $2,54 \%$ do total da área de estudo. Estes setores se localizam nas áreas de difícil acesso por apresentar vegetação de ambientes alagados e pantanosos.

A vegetação é restritiva em 27.055,77 $\mathrm{km}^{2}$ que representam $33,89 \%$ do total da área de estudo, localizados no piedemonte da bacia hidrográfica com ênfase em sua porção central.

Condições adequadas de circulação ocorrem em 157,42 km² que representam 6,46\% do total da área de estudo, localizados na parte norte da bacia.

As condições são ótimas em uma área de $12.583,41 \mathrm{~km}^{2}$ que representam $15,76 \%$ do total da área de estudo e se encontram predominantemente localizados na parte noroeste da bacia hidrográfica, onde a cobertura vegetal é escassa.

\section{ANÁLISE INTEGRADA DE MOBILIDADE BLINDADA SOBRE LAGARTAS A PARTIR DOS ELEMENTOS ANALISADOS}

O cruzamento dos parâmetros analisados permitiu a hierarquização por escala de valores, representados por diferença de tonalidade, onde as áreas próximas a 0 que representam os setores com maior grau de resistência foram associadas aos tons escuros, enquanto as próximas ao valor de 256 que representam os setores adequados, foram associados aos tons claros (Figura 12). 


\section{GEOTECNOLOGIAS E ANALISE ESPACIAL: PLANEJAMENTO DE MOBILIDADE COM UNIDADES BLINDADAS TIPO LAGARTA NA BACIA HIDROGRÁFICA DO LAGO DE MARACAIBO - VENEZUELA}

Por meio do agrupamento por níveis de homogeneidade, ante a mobilidade blindada sobre lagartas, foram discriminadas as cinco classes de restrições presentes na área de estudo.

As áreas impeditivas constituem setores que representam $65,73 \%$ da área total da bacia hidrográfica, onde a mobilidade blindada sobre lagartas em sua condição natural (sem apoio de engenharia militar) não pode ser empregue devido às limitações técnicas de construção associadas ao peso e capacidade máxima de superar.

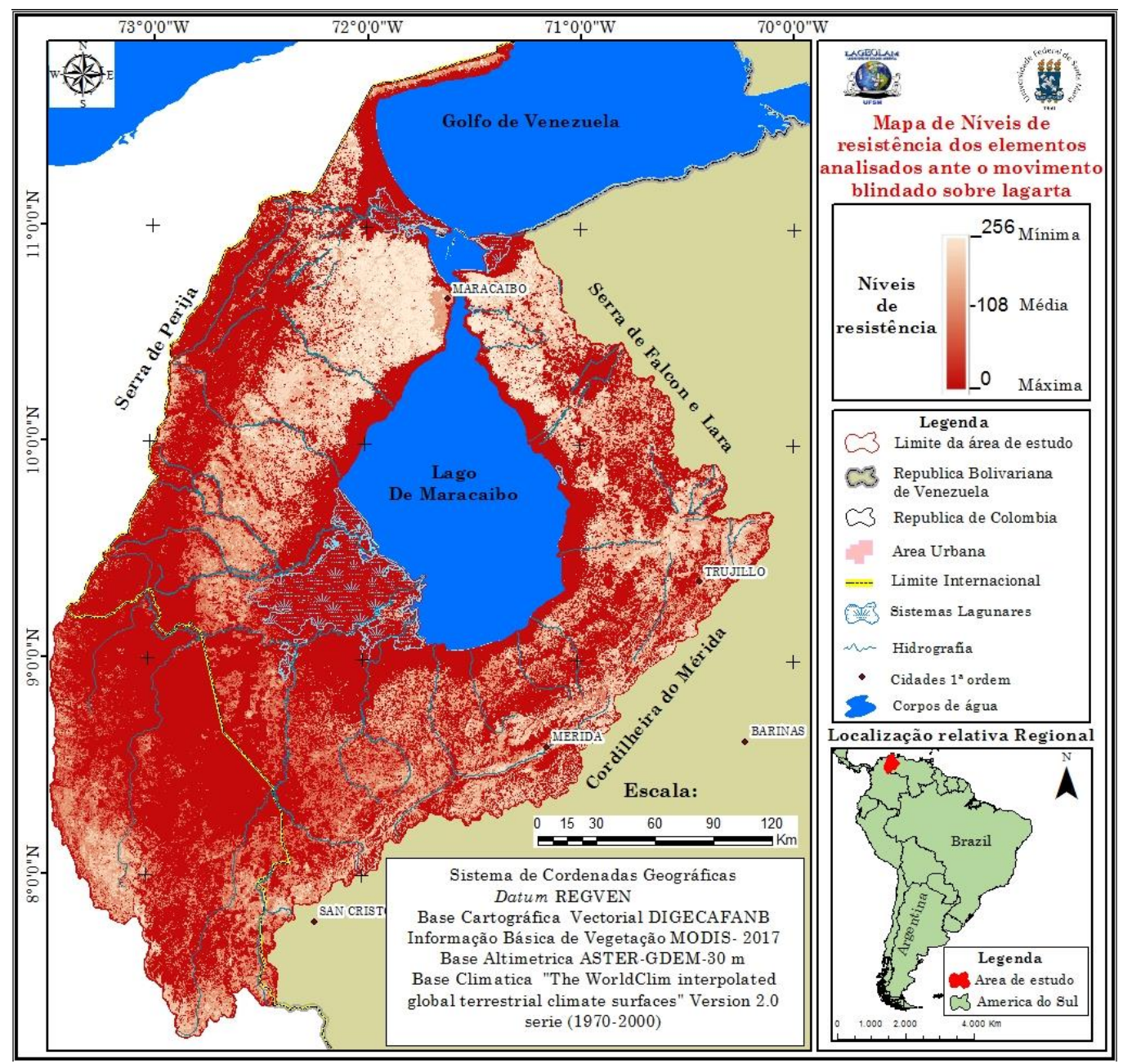

Figura 12 - Mapa dos níveis de resistência dos elementos analisados ante o movimento blindado sobre lagarta. Fonte: Os autores

Áreas restritivas e muito restritivas ocorrem em 17.132,46 $\mathrm{km}^{2}$ que representam $21,46 \%$ do total da área da bacia, localizados predominantemente nos setores de piedemonte que circunda a planície aluvial, onde a mobilidade de unidades blindadas sobre lagartas se vê notavelmente limitada comprometendo a eficiência operativa deste tipo de tecnologia militar.
As áreas adequadas ocorrem em $5.006,79 \mathrm{~km}^{2}$ e estão localizados na parte norte da área de estudo, onde apesar de não constituir obstáculos para esta tecnologia de mobilidade, repercute na eficiência dos deslocamentos.

A condição de mobilidade blindada, sobre lagartas, atinge seus maiores graus de eficiência operativa na parte norte da bacia hidrográfica, com $5.223,81 \mathrm{~km}^{2}$, onde os solos, a 


\section{GEOTECNOLOGIAS E ANALISE ESPACIAL: PLANEJAMENTO DE MOBILIDADE COM UNIDADES BLINDADAS TIPO LAGARTA NA BACIA HIDROGRÁFICA DO LAGO DE MARACAIBO - VENEZUELA}

hidrografia, a precipitação e a vegetação geraram a conformação de uma área de operação.

A Figura 13 representa o mapa de classificação dos elementos analisados por áreas de resistência homogêneas ante a mobilidade blindada sobre lagartas da bacia hidrográfica do Lago de Maracaibo.

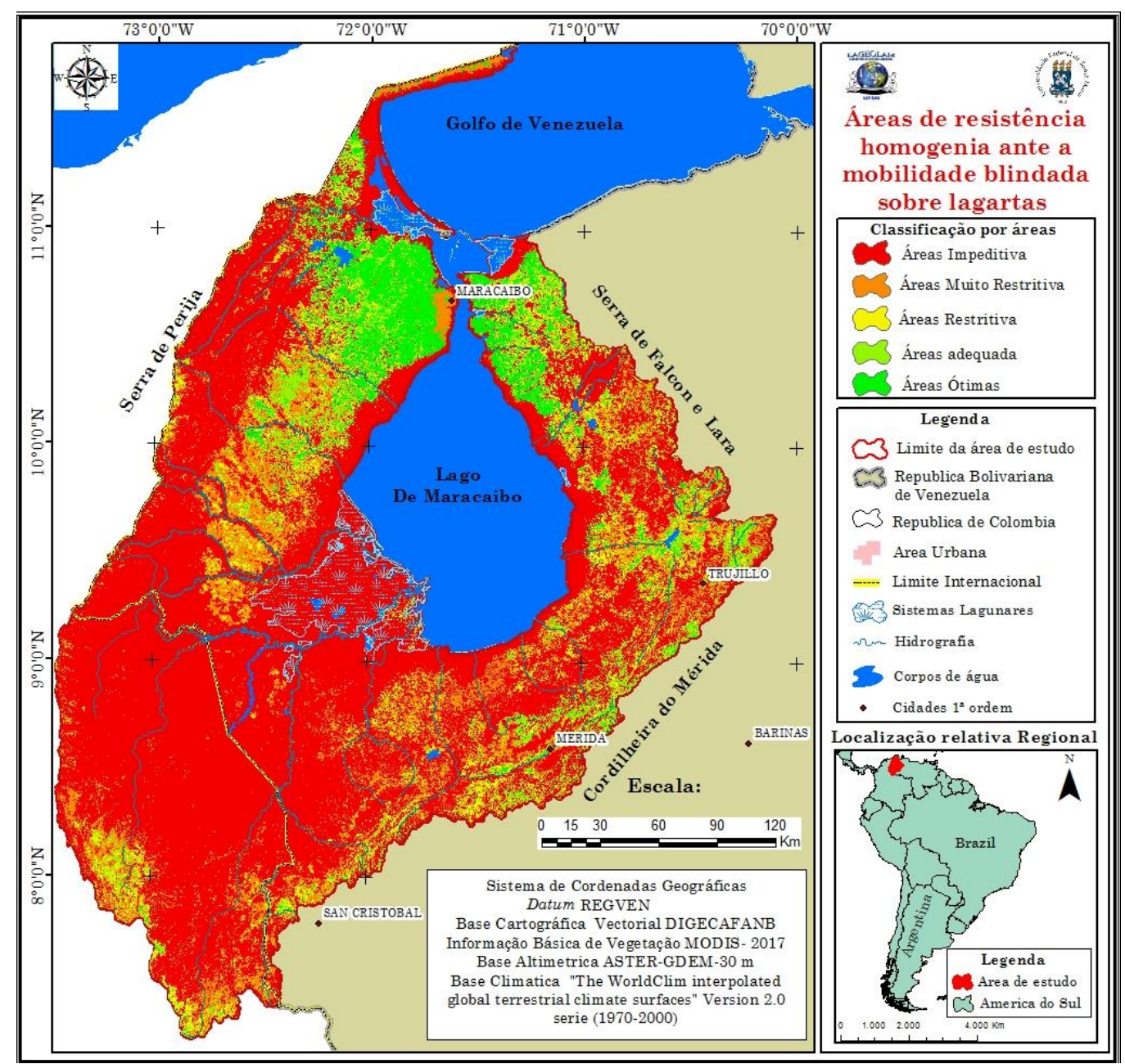

Figura 13 - Áreas de resistência homogêneas ante a mobilidade blindada sobre lagartas na área de estudo. Fonte: Os autores

O Quadro 5 representa a sínteses dos parâmetros considerados para a classificação das áreas de resistência homogêneas da mobilidade blindada sobre lagarta na bacia hidrográfica do Lago de Maracaibo. 


\section{GEOTECNOLOGIAS E ANALISE ESPACIAL: PLANEJAMENTO DE MOBILIDADE COM UNIDADES BLINDADAS TIPO LAGARTA NA BACIA HIDROGRÁFICA DO LAGO DE MARACAIBO - VENEZUELA}

Quadro 5 - Síntese dos parâmetros conceituados para a classificação da área de estudo

\begin{tabular}{|c|c|c|c|c|c|c|}
\hline Áreas & $\begin{array}{c}\text { Ambientes } \\
\text { formadores de } \\
\text { solos }\end{array}$ & Hidrografia & $\begin{array}{l}\text { Precipitação } \\
\text { acumulada }\end{array}$ & $\begin{array}{c}\text { Vegetação } \\
\text { NDVI }\end{array}$ & $\begin{array}{l}\text { Área } \\
\left(\mathrm{km}^{2}\right)\end{array}$ & $\begin{array}{c}\text { Porcentagem } \\
\text { (\%) }\end{array}$ \\
\hline Ótimas & $\begin{array}{l}\text { Declividades }<15 \% \\
\text { com planos } \\
\text { divergentes; } \\
\text { Unidades } \\
\text { Geomorfométricas } \\
3 \text { e } 4\end{array}$ & $\begin{array}{l}\text { Primeira } 1 \text { e } \\
\text { segunda } 2 \\
\text { Ordem }\end{array}$ & $<1.032 \mathrm{~mm}$ & $\begin{array}{l}\text { Solos } \\
(<0,38)\end{array}$ & $\begin{array}{c}5.223,8 \\
1\end{array}$ & 6,54 \\
\hline Adequadas & $\begin{array}{c}\text { Declividades }<15 \% \\
\text { com planos } \\
\text { convergentes; } \\
\text { Unidade } \\
\text { Geomorfométricas } \\
2 \\
\end{array}$ & $\begin{array}{l}\text { Terceira (3) } \\
\text { Ordem }\end{array}$ & $\begin{array}{c}(1.032- \\
1.371) \mathrm{mm}\end{array}$ & $\begin{array}{l}\text { Espinales } \\
\text { ralos } \\
(0,38-0,61)\end{array}$ & $\begin{array}{c}5.006,7 \\
9\end{array}$ & 6,27 \\
\hline Restritiva & $\begin{array}{c}\text { Declividades entre } \\
\text { (15\% - 45\%); } \\
\text { Unidades } \\
\text { Geomorfométricas } \\
\text { 5; } 6 \text { e } 8\end{array}$ & $\begin{array}{l}\text { Quarta (4) } \\
\text { Ordem }\end{array}$ & $\begin{array}{c}1.371-1.768) \\
\mathrm{mm}\end{array}$ & $\begin{array}{c}\text { Espinales } \\
\text { densos e } \\
\text { Bosques } \\
\text { com alta } \\
\text { intervenção } \\
(0,61-0,75) \\
\end{array}$ & $\begin{array}{c}5.829,5 \\
7\end{array}$ & 7,30 \\
\hline $\begin{array}{l}\text { Muito } \\
\text { restritiva }\end{array}$ & $\begin{array}{c}\text { Declividades }>45 \% \\
\text { Unidade } \\
\text { Geomorfométrica } 7\end{array}$ & $\begin{array}{l}\text { Quinta (5) } \\
\text { Ordem }\end{array}$ & $\begin{array}{c}(1.768- \\
2.255) \mathrm{mm}\end{array}$ & $\begin{array}{c}\text { Bosques } \\
\text { com alta } \\
\text { intervenção } \\
(0,61-0,85)\end{array}$ & $\begin{array}{c}11.302 \\
89\end{array}$ & 14,16 \\
\hline Impeditivas & $\begin{array}{c}\text { Alturas } \leq 0 \text { metros } \\
\text { Declividades }>45 \\
\% \text {; Unidades } \\
\text { Geomorfométricas } \\
1 \text { e } 9\end{array}$ & $\begin{array}{l}\text { Sexta (6) } \\
\text { Ordem }\end{array}$ & $>2.255 \mathrm{~mm}$ & $\begin{array}{l}\text { Bosques } \\
\text { densos } \\
(>0,85)\end{array}$ & $\begin{array}{c}52.481 \\
87\end{array}$ & 65,73 \\
\hline \multicolumn{5}{|c|}{ TOTAL } & $\begin{array}{c}79.844 \\
92\end{array}$ & 100,00 \\
\hline
\end{tabular}

\section{CONSIDERAÇÕES FINAIS}

O trabalho estabelece uma análise regional de aplicação. A bacia hidrográfica do Lago Maracaibo apresenta uma importante área de estratégia militar da Venezuela, desta forma utilizou-se bases cartográfica generalistas e metodologias de definição de áreas adequadas, restritivas e impeditivas também generalistas, visando a definição de grandes áreas e setorização na referida bacia hidrográfica. Trabalhos de detalhamentos, são extremamente necessários e para isso será necessário também a utilização de bases cartográficas e parâmetros metodológicos que considerem elementos de maior escala.

A análise geográfica realizada permitiu espacializar, em escala regional, áreas com diferentes graus de trafegabilidade para veículos blindados propulsados sobre Lagartas, com base em variáveis físico-naturais da Bacia Hidrográfica do Lago de Maracaibo.

A eficiência da aplicação de ferramentas computacionais para subsidiar os processos de tomada de decisão, em ambientes operacionais, depende da correta avaliação geográfica, a qual varia com os tipos de tecnologias e as características geográficas de cada área de operação, incluindo suas alterações temporárias como por exemplo as pluviométricas que variam consideravelmente os graus de resistência ao movimento exercido pelos solos.

A complexidade das análises geográficas de índole militar reafirma a importância do especialista em geografia cuja formação, tanto acadêmica como profissional lhe permitirá relacionar eficientemente variáveis do ambiente com as necessidades da tropa e com as atividades operacionais. 


\section{GEOTECNOLOGIAS E ANALISE ESPACIAL: PLANEJAMENTO DE MOBILIDADE COM UNIDADES BLINDADAS TIPO LAGARTA NA BACIA HIDROGRÁFICA DO LAGO DE MARACAIBO - VENEZUELA}

O trabalho apresenta uma análise regional que permite realizar a extração de informações de diversas naturezas de forma rápida e atualizada sobre qualquer área antes das atividades de operação

\section{REFERÊNCIAS}

BRASIL. Ministério da Defesa, Exército Brasileiro. Diretriz de Trafegabilidade para Viaturas sobre Rodas e sobre Lagartas. Brasília, 2011.

DRAGUT, L; BLASCHKE, T. Automated classification of landform elements using objectbased image analysis. Geomorphology, 81, 330$344,2006$.

GALLANT, A. L.; BROWN, D. D.; HOFFER, R. M. Automated Mapping of Hammond's Landforms. IEEE Geoscience And Remote Sensing Letters, vol. 2, n. 4, p. 384-388, 2005.

GROHMANN, C. H.; SAWAKUCHI, A. O. Influence of cell size on volume calculation using digital terrain models: A case of coastal dune fields. Geomorphology 180-181, p. 130-136, 2013.

HANI, A. F. M.; SATHYAMOORTHY, D.; ASIRVADAM, V. S. Computing surface roughness of individual cells of Digital Elevation Models via multiscale analysis. Computers \& Geosciences 43, p. 137-146, 2012.

HOEPERS, G.; SANTOS, N. A. O Geoprocessamento Aplicado ao Método de Estudo Militar do Terreno. 2001. 98 f. Monografia (Especialização em Geoprocessamento) Laboratório de Sensoriamento Remoto, Instituto de Geociências, Universidade de Brasília, Brasília, DF, 2001.

IVANOV, M. A. et al. Geomorphometric analysis of river basins in East European Russia using SRTM and ASTER GDEM data. Journal of Engineering and Applied Sciences, 2016.

JASIEWICZ, J.; STEPINSKI, T. F. Geomorphons a Pattern Recognition Approach to Classification and Mapping of Landforms. Geomorphology, 182. 2013. Pag. 147-156

MACMILLAN, R. A.; SHARY, P. A. Landforms and Landform Elements in Geomorphometry. In: HENGL, T.; REUTER, H. I. Geomorphometry: Concepts, Software, Applications.Elsevier, v. 33, 2009. Cap. 9, p. 227-254.
MCKENZIE, N. J.; GESSLER, P. E.; RYAN, P. J; O'CONNEL, D.. The role of terrain analysis in soil mapping. In: Wilson, J.P. Gallan, J.C.(Eds.) Terrain Analysis Principle and Applications. Wiley, New York, p.245-265.2000.

NICULITǍ, M. Effects of geomorphometric variables variability due to different computing algorithms in environmental modeling. Procedia Environmental Sciences. 2011

NOGUERA, N. et al. I Caracterización química y mineralógica de los suelos de la colección centro de información y referencia de suelos para la Cuenca del Lago de Maracaibo. Venesuelos, v. 2, n. 2, p. 67-80, 2011.

RIBEIRO, F. G. A Geografia Militar no Brasil: a questão da defesa nacional. 2015. 269 f. Tese (Doutorado em Geografia Humana)-Universidade de São Paulo, São Paulo, 2015.

ROBAINA, L. E.S.; TRENTIN, R.; LAURENT, F. Compartimentação do estado do Rio Grande do Sul, Brasil, através do uso de geomorphons obtidos em classificação topográfica automatizada. Revista Brasileira de Geomorfologia, v.17, n.2, (Abr-Jun) p. 287-298, 2016

ROBAINA, L. E.S.; TRENTIN, R.; CRISTO, S. S. V.; SCCOTI, A. A. V. Application of the geomorphons to the landform classification in Tocantins state, Brazil. Revista Ra'Ega, v.41, p.37-48, 2017.

SILVEIRA, R.; SILVEIRA, C. Clasificación Morfológica del Relieve de Uruguayo Basada en Modelos Digitales de Elevación y Técnicas Geomorfométricas. Geografía y Sistemas de Información Geográfica (GEOSIG), Luján, v. 6, n. 6, p. 19-36, 2014.

SOARES, I.C. O uso da análise espacial no Processo de Integração Terreno, Condições Meteorológicas e Inimigo (PITCI) do Exército Brasileiro. 2006. 94 p. Dissertação (Mestrado em Geociências)-Universidade de Brasília, Brasília, 2006.

VASCONCELOS,V.; CARVALHO JÚNIOR, O.A.; MARTINS, E. S; COUTO JUNIOR, A. F.; GUIMARÃES, R.F.; GOMES, R.A,T. Sistema de classificação geomorfométrica baseado em uma arquitetura sequencial em duas etapas: árvore de decisão e classificador espectral, no Parque Nacional Serra da Canastra. Revista Brasileira de 


\section{GEOTECNOLOGIAS E ANALISE ESPACIAL: PLANEJAMENTO DE MOBILIDADE COM UNIDADES BLINDADAS TIPO LAGARTA NA BACIA HIDROGRÁFICA DO LAGO DE MARACAIBO - VENEZUELA}

Geomorfologia, v.13, n.2, (Abr-Jun) p.171-186, 2012

VENEZUELA. Ministério da Defesa, Universidade Militar - Escola do Exército. Manual de Geografia Militar. Caracas, 1992.

VENEZUELA. Ministerio de Minas e Hidrocarburos. Dirección de Geología, Relieve, Formaciones Geológicas, Sectorización y Geomorfología. Caracas, DC, 1969.

VENEZUELA. Ministerio del Ambiente y los Recursos Naturales Renovables. Estudio Integral sobre la Contaminación del Lago de Maracaibo y sus Afluentes. Caracas, DC,1979.
ROBAINA, L. E.S.; TRENTIN, R.; LAURENT, F. Compartimentação do estado do Rio Grande do Sul, Brasil, através do uso de geomorphons obtidos em classificação topográfica automatizada. Revista Brasileira de Geomorfologia, v.17, n.2, (Abr-Jun) p. 287-298, 2016

ROBAINA, L. E.S.; TRENTIN, R.; CRISTO, S. S. V.; SCCOTI, A. A. V. Application of the geomorphons to the landform classification in Tocantins state, Brazil. Revista Ra'Ega, v.41, p.37-48, 2017. 